\title{
Differential pharmacology and benefit/risk of azilsartan compared to other sartans
}

\author{
This article was published in the following Dove Press journal: \\ Vascular Health and Risk Management \\ 27 February 2012 \\ Number of times this article has been viewed
}

\author{
Theodore W Kurtz' \\ Takashi Kajiya ${ }^{2}$ \\ 'Department of Laboratory Medicine, \\ University of California, San \\ Francisco, CA, USA; ${ }^{2}$ Department \\ of Cardiovascular, Respiratory, and \\ Metabolic Medicine, Graduate School \\ of Medicine, Kagoshima University, \\ Kagoshima, Japan
}

\begin{abstract}
Azilsartan, an angiotensin II type $1\left(\mathrm{AT}_{1}\right)$ receptor blocker (ARB), was recently approved by regulatory authorities for treatment of hypertension and is the 8th ARB to join the clinical market. This article discusses the medical reasons for introducing a new $\mathrm{AT}_{1}$ receptor blocker and reviews the experimental and clinical studies that have compared the functional properties of azilsartan to those of other ARBs. The main question addressed is: Does azilsartan have distinguishing features that should motivate choosing it over any of the other sartans for use in clinical practice? Based on studies conducted to date in hypertensive patients without serious comorbidities, azilsartan appears to be characterized by a superior ability to control 24-hour systolic blood pressure (BP) relative to other widely used ARBs including valsartan, olmesartan, and candesartan, and presumably others as well (eg, losartan). Compared to these other ARBs, azilsartan may increase the BP target control and response rate by an absolute value of $8 \%-10 \%$. Greater antihypertensive effects of azilsartan might be due in part to its unusually potent and persistent ability to inhibit binding of angiotensin II to $\mathrm{AT}_{1}$ receptors. Preclinical studies have indicated that azilsartan may also have potentially beneficial effects on cellular mechanisms of cardiometabolic disease and insulin sensitizing activity that could involve more than just blockade of $\mathrm{AT}_{1}$ receptors and/or reduction in BP. However, the clinical relevance of these additional actions is unknown. Given that the general ability of antihypertensive drugs to protect against target organ damage is largely mediated by their ability to decrease BP, the enhanced antihypertensive effects of azilsartan should serve to justify clinical interest in this ARB relative to other molecules in the class that have a lower capacity to reduce BP.

Keywords: azilsartan, azilsartan medoxomil, angiotensin II type 1 receptor blockers, angiotensins, hypertension, TAK-491, TAK-536, candesartan, olmesartan, valsartan, losartan, telmisartan, irbesartan, eprosartan
\end{abstract}

\section{Introduction and background}

Nonpeptide antagonists of the angiotensin II type $1\left(\mathrm{AT}_{1}\right)$ receptor constitute a very useful and widely prescribed class of antihypertensive drugs. ${ }^{1}$ The development of $\mathrm{AT}_{1}$ receptor blockers (ARBs) can be traced back to the pioneering work of scientists at Takeda Pharmaceuticals who described a series of benzylimidazole compounds that inhibited the ability of angiotensin II to stimulate vascular contraction and increase blood pressure (BP). ${ }^{2,3}$ Using a modeling strategy based on the original Takeda compounds, scientists at DuPont derived losartan, the first ARB introduced for the clinical treatment of hypertension. ${ }^{4}$ After the Food and Drug Administration (FDA) approved losartan in 1995, a host of other $\mathrm{AT}_{1}$ receptor antagonists were rapidly introduced and a total of six ARBs were already clinically available by the time olmesartan medoxomil joined the market
Correspondence:Theodore W Kurtz UCSF Department of Laboratory Medicine, 185 Berry Street, Suite 290 San Francisco, CA 94107, USA

Tel +l 4I5 3531979

$\mathrm{Fax}+18019123103$

Email kurtzt@labmed2.ucsf.edu which permits unrestricted noncommercial use, provided the original work is properly cited. 
in 2002. More than 15 years after the clinical introduction of losartan, the FDA approved Takeda's azilsartan medoxomil as the 8th ARB for the treatment of hypertension. ${ }^{5}$ Azilsartan medoxomil has also been approved in Europe for treatment of hypertension and the parent compound, azilsartan, has recently been approved in Japan. ${ }^{6,7}$

The purpose of this paper is to address two related questions: (1) Why develop another $\mathrm{AT}_{1}$ receptor antagonist for clinical practice when over a half dozen ARBs are already clinically available? (2) Is there anything special about the most recently approved ARB azilsartan compared to the old "standbys" that have been in clinical use for many years?

\section{Principal reasons for developing another ARB \\ To achieve better control of BP than that provided by other ARBs}

Much has been written about the putative benefits of ARBs mediated by mechanisms said to be independent of reductions in BP. However, the ability of ARBs to protect against target organ damage and improve clinical outcomes is still considered to be largely mediated by their ability to decrease BP. ${ }^{8,9}$ Because it is the decrease in BP that is believed to be mainly responsible for the clinical cardiovascular $(\mathrm{CV})$ benefits of all types of antihypertensive drugs, the FDA recently permitted pharmaceutical companies to make the "general, qualitative claim of cardiovascular outcome benefits" for approved antihypertensive drugs without requiring companies to submit clinical cardiovascular outcome data for such drugs. ${ }^{10}$ This appears to be the first time that the FDA has consented to "extending an outcome claim across a set of pharmacologically distinct drug classes." In essence, the FDA has accepted BP-lowering that meets regulatory standards as a surrogate for reduction in fatal and nonfatal cardiovascular events, primarily strokes and myocardial infarctions. ${ }^{10}$ Although the FDA's position is not directly relevant for regulatory purposes outside of the USA, it is scientifically consistent with the position statements of major hypertension authorities in other parts of the world. For example, experts representing the European Society of Hypertension have also concluded that "the main benefits of antihypertensive treatment are due to lowering of BP per se, and are largely independent of the drugs employed." 11

Despite the fact that all approved $\mathrm{AT}_{1}$ receptor blockers can lower BP, many patients treated with currently available ARBs do not achieve BP treatment goals. ${ }^{12-14}$ This is often due to the fact that hypertension is mediated by factors other than just increased activity of the renin angiotensin system. In some cases, however, it is also possible that patients are not achieving sufficient blockade of the renin-angiotensin system due to issues related to ARB pharmacodynamics, pharmacokinetics, and or adherence to therapy. Although treatment of hypertension with multiple drugs is helpful for controlling BP in patients in whom hypertension is determined by more than just the renin-angiotensin system, the availability of an ARB with greater ability to lower BP than older ARBs could nevertheless be of clinical value. Thus, one could medically appreciate the introduction of still another ARB if the molecule was able to safely provide better BP control and presumably therefore, better cardiovascular protection than that afforded by maximum approved doses of existing ARBs. Of course, this assumes that the particular structure of the sartan does not confer adverse effects that could undermine the cardiovascular benefits otherwise expected from its ability to block $\mathrm{AT}_{1}$ receptors and reduce $\mathrm{BP}$.

Do any of the old clinical ARBs stand out with respect to the ability to lower BP? The standard ARBs that have been clinically available for many years have long been recognized to show differences among each other with respect to factors such as plasma half-life, potency for $\mathrm{AT}_{1}$ receptor blockade, and slope of the dose response curve for lowering BP. ${ }^{15-17}$ However, in studies including endpoints reached after chronic titration to maximum approved doses of various sartans, it has been difficult to show that any one $\mathrm{ARB}$ in particular stands out with respect to the ability to lower BP. ${ }^{18}$ Head-to-head studies performed with lower drug doses beg the question as to whether any of the differences in BP-lowering capacity observed among various ARBs might simply be overcome by conventional dose adjustments that achieve maximum BP responses. Among some ARBs, differences in BP-lowering ability caused by differences in half-life and or potency for $\mathrm{AT}_{1}$ receptor blockade might be eliminated just by insuring that the maximum approved doses are consistently administered on a daily basis.

There have been several reports of head-to-head trials indicating that the maximum approved dose of losartan is less effective than the maximum approved doses of other ARBs in controlling BP through some or all portions of the 24-hour dosing interval. ${ }^{19-22}$ Even at high doses, losartan appears less effective in lowering BP than most other ARBs owing to its relatively flat dose response curve. ${ }^{23}$ Post hoc studies based on either meta-analysis of different trials lumped together, or on review of BP data from patient medical records have also indicated that losartan may be less effective than some other ARBs in reducing BP when used as monotherapy or for 
combination therapy. ${ }^{13,14,24}$ Given the paucity of head-to-head controlled clinical trials, there has been little or no definitive evidence that any ARB provides better BP control than that provided by maximum approved doses of competitors other than losartan. However, as discussed further below, recent head-to-head studies comparing azilsartan to other ARBs have changed this situation. ${ }^{25-28}$

\section{To provide significant clinical value beyond that afforded by good BP control}

Notwithstanding the consensus view that the CV outcome benefits of all antihypertensive drugs can be largely attributed to BP-lowering, it is possible that new antihypertensive drugs might be introduced with "other properties" in addition to BP-lowering that could contribute to differences in CV events and or differences in effects on other significant clinical endpoints. In fact, the FDA has stated that "individual drugs, and perhaps drug classes, may have differences in effects on other important endpoints, presumably because of pharmacological effects other than BP reduction." 10 According to the FDA, "these other properties of antihypertensive drugs (eg, effects on heart failure or diabetic nephropathy) often will be a reasonable basis for deciding which drugs to use or which drugs to use first." 10

It is well known that many factors besides BP can influence $\mathrm{CV}$ outcomes and that many patients suffer from cardiovascular events despite having their hypertension under good control with a drug that inhibits the renin angiotensin system. Clearly, multiple risk factor intervention is required for purposes of target organ protection and should be encouraged as much as possible. ${ }^{29}$ Nevertheless, one could appreciate the introduction of another $\mathrm{ARB}$ if the molecule could do more than lower BP and safely provide a significant degree of added CV protection beyond that achieved by lowering BP with typical ARBs. Unfortunately, for ARBs in general, the added cardiovascular benefits mediated through mechanisms beyond BP-lowering appear modest at best and remain open to question. ${ }^{8,29-32}$

It is generally accepted that $\mathrm{AT}_{1}$ receptor blockers can help protect against the progression of diabetic nephropathy and that some of this benefit may involve more than BPlowering. ${ }^{33}$ In addition, some ARBs may be more effective than others in reducing proteinuria in patients with diabetic nephropathy despite providing similar reductions in $\mathrm{BP}^{34}$ Nevertheless, the main renoprotective actions of ARBs in general are largely mediated by their effects on BP. ${ }^{9}$ Interestingly, the FDA has not extended a general claim of nephroprotective benefits to all molecules in the ARB class despite the fact that all approved ARBs inhibit $\mathrm{AT}_{1}$ signaling and lower BP. However, clinical practice guidelines from major medical societies treat the renal protective actions of ARBs as a class effect and recommend ARBs among the first line drugs for treatment of hypertension in diabetics. In any case, one might be motivated to select a new ARB for clinical use over existing ARBs if it could be shown to safely provide better renoprotection either through better BP control, more effective $\mathrm{AT}_{1}$ receptor blockade, or any other beneficial mechanism.

Enhanced protection from developing diabetes is another example of an added clinical benefit that might help motivate the selection of a newer ARB over existing ARBs. Although multiple risk factor intervention including nonpharmacologic and pharmacologic strategies can be useful for reducing the risk for diabetes as well as for cardiovascular disease, ${ }^{29,31,35,36}$ the presence of an extra antidiabetic effect in a reasonably priced and safe antihypertensive drug could still represent a useful clinical bonus. This is true regardless of whether or not prevention of new onset diabetes reduces cardiovascular risk, or any other physical problems, because the diagnosis itself carries psychological and practical burdens.

While it is generally believed that angiotensin receptor blockers can reduce the risk for new onset diabetes, the absolute antidiabetic effects reported so far have been rather weak. ${ }^{29,31,32,37}$ The best randomized, double blind trial on the antidiabetic effect of an $\mathrm{AT}_{1}$ receptor blocker was performed with valsartan. ${ }^{32}$ In patients with impaired glucose metabolism, valsartan afforded a relative risk reduction for incident diabetes of $12.4 \%$ after adjusting for differences from the control group for presence of metabolic syndrome at baseline and frequency in use of other antihypertensive drugs. However, the absolute risk reduction for incident diabetes with valsartan was only $3.7 \%$ and many patients taking valsartan still developed diabetes. Thus, there is clear room for improvement in the putative antidiabetic effects of $\mathrm{AT}_{1}$ receptor blockers. ${ }^{31}$

\section{Is there anything special about azilsartan? Discovery path and chemical structure} Azilsartan was discovered through the efforts of Takeda scientists to find a new class of $\mathrm{AT}_{1}$ antagonists by modifying the tetrazole ring present in candesartan. ${ }^{38,39}$ The tetrazole ring is also present in many other clinically approved ARBs including irbesartan, olmesartan, losartan, and valsartan. As shown in Figure 1, the chemical structure of azilsartan is very similar to the structure of candesartan and differs only by replacement 
of candesartan's 5 member tetrazole ring with the 5 member oxo-oxadiazole ring of azilsartan. This chemical modification served to make azilsartan less acidic and more lipophilic than candesartan. The oxo-oxadiazole ring in azilsartan is not found in any other clinically approved ARB.

Unlike candesartan, which must be orally administered as the prodrug candesartan cilexetil to insure adequate bioavailability, azilsartan has been shown to be effective in reducing BP when orally administered as either the ester prodrug, azilsartan medoxomil (TAK-491), or as the primary compound. ${ }^{28,38,40,41}$ During gastrointestinal absorption, azilsartan medoxomil is rapidly hydrolyzed to azilsartan (TAK-536), the bioactive molecule that selectively and competitively blocks angiotensin II-induced activation of $\mathrm{AT}_{1}$ receptors in an insurmountable fashion. ${ }^{5,38,42,43}$ The prodrug azilsartan medoxomil has never been detected in plasma after oral administration to humans. Azilsartan is metabolized to major (M-II) and minor (M-I) metabolites that do not significantly contribute to $\mathrm{AT}_{1}$ receptor blockade. ${ }^{5,25}$

Azilsartan medoxomil has been approved in both the United States and Europe for treatment of hypertension. ${ }^{5,6}$ In 2012, the parent compound azilsartan was approved in Japan for treatment of hypertension. ${ }^{7}$ There is nothing particularly remarkable about the pharmacokinetic features or safety profiles of azilsartan or azilsartan medoxomil versus other ARBs. Azilsartan is a well-tolerated molecule with a half-life of approximately 11 hours, is metabolized in the liver mainly via cytochrome P450 2C9 (CYP2C9), and is eliminated in both urine and feces. ${ }^{5,41}$ No unusual drug interactions have been observed with azilsartan or azilsartan medoxomil, and dosage adjustment is not required in patients with mild to severe renal disease or in patients with mild to moderate hepatic impairment. ${ }^{5,41}$

\section{Greater antihypertensive effects of azilsartan than other ARBs}

Azilsartan, in clinically approved doses as azilsartan medoxomil, has been shown to lower 24-hour BP in hypertensive patients significantly more than the maximum approved dose of olmesartan medoxomil, the latter being considered by some to be one of the most potent ARBs for lowering BP. ${ }^{23,25,26}$ Azilsartan medoxomil has also been shown to lower 24-hour BP significantly more than the maximum approved dose of valsartan, the most widely prescribed drug in the ARB class. ${ }^{25,27,44}$ Specifically, in head-to-head studies using ambulatory BP monitoring in hypertensive patients without serious comorbidities, treatment for 6 weeks with $80 \mathrm{mg}$ azilsartan medoxomil lowered 24-hour systolic BP by $2-4 \mathrm{mmHg}(P<0.01$ to $P<0.001)$ more than $40 \mathrm{mg}$ olmesartan medoxomil or $320 \mathrm{mg}$ valsartan, respectively (Figure 2). ${ }^{25,26}$ Azilsartan medoxomil also lowered 24-hour diastolic BP more than olmesartan medoxomil and valsartan, and was just as well tolerated and as safe as the comparator agents.

In a longer study comparing azilsartan medoxomil to valsartan, treatment with either $40 \mathrm{mg}$ or $80 \mathrm{mg}$ azilsartan medoxomil for 24 weeks reduced 24-hour systolic BP and clinic systolic BP significantly more than $320 \mathrm{mg}$ valsartan $(\sim 4 \mathrm{mmHg}){ }^{27}$ Based on the results of both epidemiologic studies and intervention trials, various authorities have

\section{Candesartan}

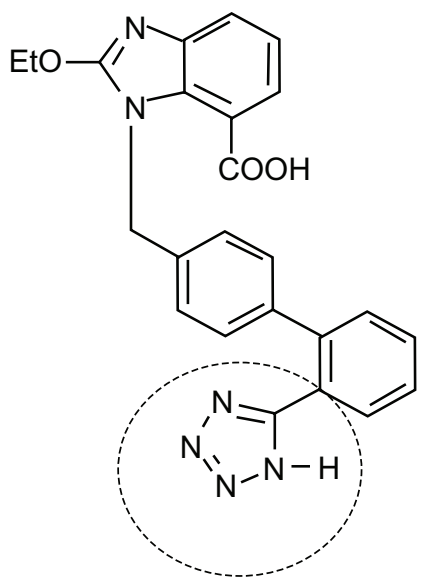

\section{Azilsartan}

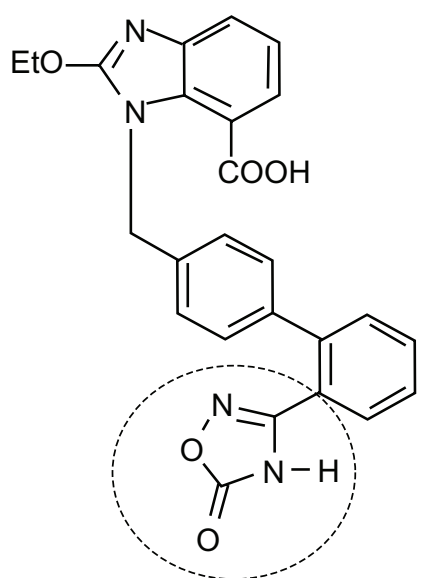

Figure I Chemical structure of azilsartan compared to candesartan. The structures of azilsartan and candesartan are identical except that azilsartan has a 5-oxo-I,2, 4-oxadiazole ring in place of the tetrazole ring found in candesartan and in many other ARBs including valsartan, olmesartan, losartan, and irbesartan. The 5-oxo-1,2, 4-oxadiazole ring in azilsartan and the tetrazole ring in candesartan are highlighted in the dashed circles. 


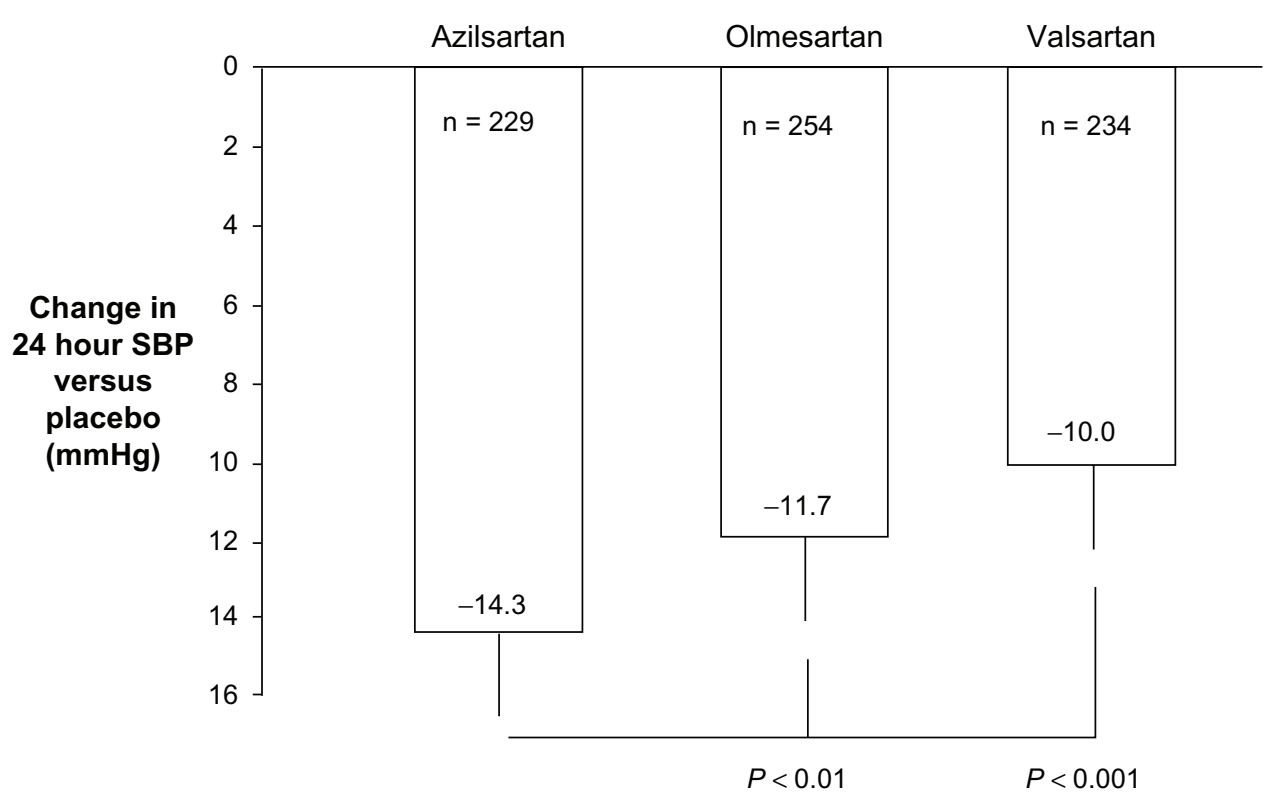

Figure 2 Mean changes in 24-hour systolic BP from baseline (difference from placebo) in patients with stages I and 2 hypertension without serious comorbidities treated for 6 weeks with maximum approved doses of azilsartan medoxomil $(80 \mathrm{mg} /$ day), olmesartan medoxomil $(40 \mathrm{mg} / \mathrm{day})$, or valsartan ( $320 \mathrm{mg} / \mathrm{day})$ as reported by White et al. ${ }^{25}$ Error bars denote limits of the $95 \%$ confidence intervals for the means.

Abbreviation: BP, blood pressure.

indicated that this magnitude of additional BP-lowering may contribute to further reduction in cardiovascular risk. ${ }^{45,46}$

In the head-to-head studies comparing BP effects of different ARBs in patients with stages 1 and 2 hypertension and without serious comorbidities, White et al noted that more subjects achieved a clinic SBP goal of $<140 \mathrm{mmHg}$ and or a $>20 \mathrm{mmHg}$ reduction in SBP from baseline during treatment with azilsartan medoxomil ( $58 \%$ of patients) than with maximum approved doses of olmesartan or valsartan (49\% of patients, $P<0.05$ ). ${ }^{25}$ Greater BP-lowering effects with azilsartan versus olmesartan or valsartan were observed in a variety of patient groups including those either $<65$ or $>65$ years of age, in black subjects or white subjects, males or females, and in obese and nonobese subjects.

Given the close structural relationship between azilsartan and candesartan, head-to-head studies comparing the BP effects of these two drugs are of particular interest. Recently, Rakugi et al reported that in a 16 week, randomized, double blind study of 622 Japanese patients with grade I-II essential hypertension, azilsartan, 20-40 mg per day by forced titration, lowered clinic systolic and diastolic BPs significantly more than candesartan cilexetil, 8-12 mg per day by forced titration (Figure 3). ${ }^{28}$ Ambulatory BP monitoring at week 14 confirmed superior antihypertensive effects of azilsartan versus candesartan cilexetil over the 24-hour period, and during the daytime, night-time, and early morning. It should be noted that patients with cardiovascular disease or significant renal or hepatic disease were excluded from this trial.
However, approximately $20 \%$ of the subjects had diabetes, and greater BP effects of azilsartan versus candesartan cilexetil were observed in both the diabetic patients and the nondiabetic patients. Results for safety and tolerability were similar in patients treated with azilsartan versus those treated with candesartan cilexetil. In Japan, $40 \mathrm{mg} /$ day is the maximum approved dose for azilsartan and $12 \mathrm{mg} /$ day is the maximum approved dose for candesartan cilexetil. ${ }^{7,28}$

The clinical BP trials of azilsartan or azilsartan medoxomil published to date have been mainly conducted in patients without serious comorbidities, although $20 \%$ of the subjects in the study by Rakugi et al were diabetic. ${ }^{28}$ It remains to be determined whether azilsartan will also provide superior BP-lowering action, or any type of advantage over other ARBs in the treatment of hypertensive patients with serious comorbidities such as cardiovascular disease or severe renal insufficiency. Although head-to-head comparisons of the BP-lowering actions of different ARBs in high risk patients are certainly feasible, it is unlikely that large scale trials will ever be performed to compare the effects of different ARBs on clinical outcomes such as myocardial infarction, renal failure, stroke, etc.

No head-to-head BP studies have been published that tested azilsartan in combination with a diuretic or calcium blocker versus other ARBs in combination with exactly the same comparator diuretic or calcium blocker. Azilsartan medoxomil is the only ARB that has been approved for use in a fixed dose combination with the diuretic chlorthalidone 


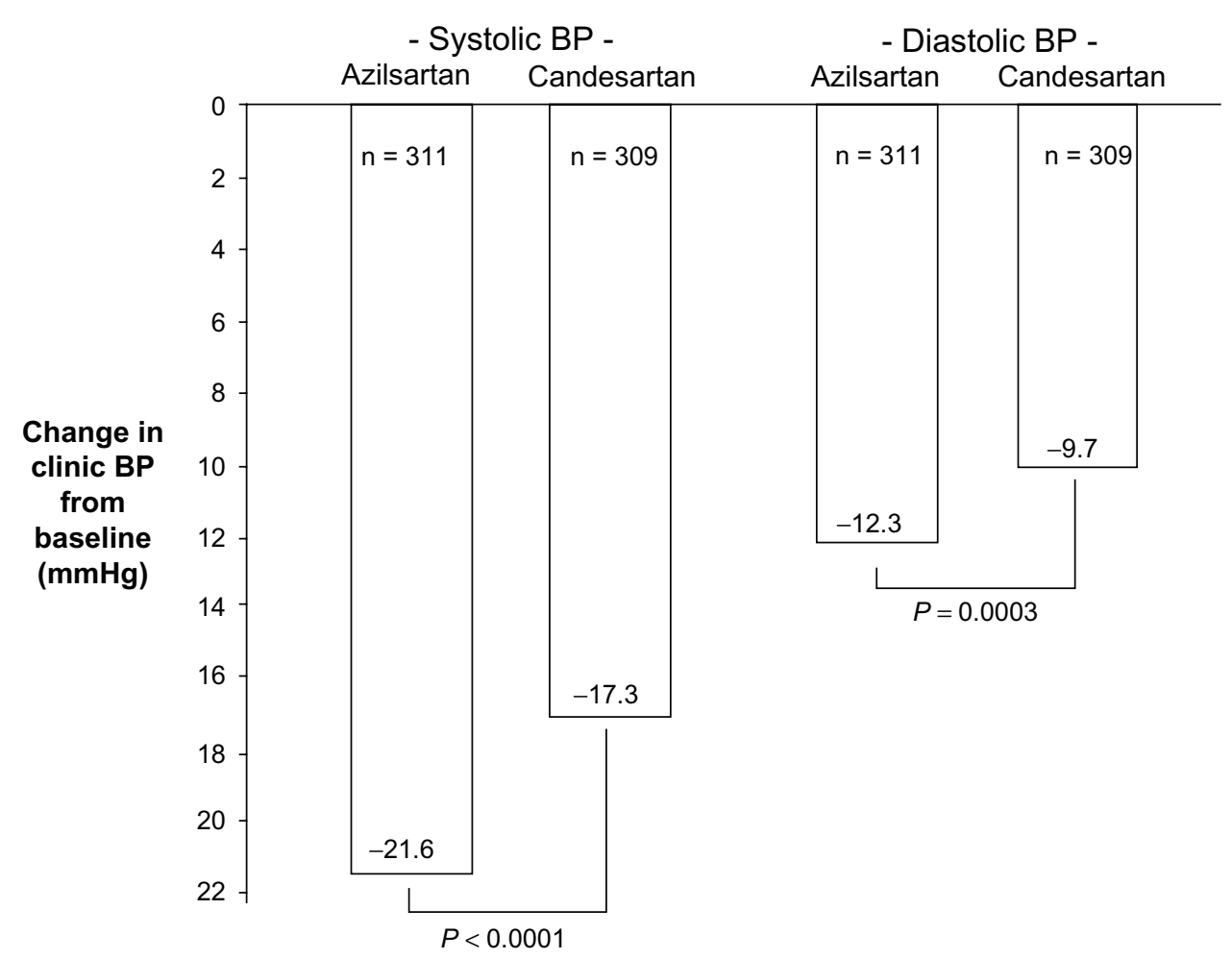

Figure 3 Changes in clinic systolic and diastolic BPs from baseline in Japanese patients with grade I-II essential hypertension after treatment for I6 weeks with azilsartan or candesartan cilexetil as reported by Rakugi et al. ${ }^{28}$ Patients received either azilsartan, $20 \mathrm{mg} /$ day for 8 weeks followed by $40 \mathrm{mg} /$ day for an additional 8 weeks, or candesartan cilexetil, $8 \mathrm{mg} /$ day for 8 weeks followed by $12 \mathrm{mg} /$ day for an additional 8 weeks. In Japan, the maximum approved dose of azilsartan is $40 \mathrm{mg} /$ day and the maximum approved dose of candesartan cilexetil is $12 \mathrm{mg} /$ day. Approximately $20 \%$ of study patients had diabetes. Patients with known cardiovascular disease or significant hepatic or renal disease were excluded from the study.

Abbreviation: BP, blood pressure.

whereas other ARBs are sold in fixed dose combinations with hydrochlorothiazide. This is noteworthy because of evidence indicating that typically used doses of chlorthalidone are more effective in lowering BP and may afford greater CV protection than typically used doses of hydrochlorothiazide. ${ }^{47,48} \mathrm{In}$ a head-to-head, randomized trial, the combination of $40 \mathrm{mg}$ azilsartan medoxomil plus $25 \mathrm{mg}$ chlorthalidone was found to lower BP significantly more than the combination of $40 \mathrm{mg}$ olmesartan medoxomil plus $25 \mathrm{mg}$ hydrochlorothiazide. ${ }^{49}$

\section{Greater potency of azilsartan for AT, receptor blockade and potential relevance to its superior BP-lowering properties}

Similar to other ARBs, azilsartan is highly selective for $\mathrm{AT}_{1}$ receptors and has more than a 10,000-fold greater affinity for $\mathrm{AT}_{1}$ versus $\mathrm{AT}_{2}$ receptors. ${ }^{50}$ Like many other $\mathrm{ARBs}$, azilsartan not only functions as a selective and competitive antagonist that blocks angiotensin II stimulation of $\mathrm{AT}_{1}$ receptors in an insurmountable fashion, it can also act as an inverse agonist and inhibit $\mathrm{AT}_{1}$ receptor signaling that may occur in the absence of angiotensin $\mathrm{II}^{42}$ Although other ARBs can also potently and selectively interfere with angiotensin II induced activation of $\mathrm{AT}_{1}$ receptors in an insurmountable fashion, azilsartan appears to be characterized by a greater potency and an unusual capacity to persistently block $\mathrm{AT}_{1}$ receptors for longer periods of time than most, if not all, competitor ARBs. ${ }^{42,43}$

Table 1 shows the concentrations $\left(\mathrm{IC}_{50}\right.$ values) of different ARBs required to inhibit binding by $50 \%$ of radioactively

Table I Concentrations of ARBs that inhibit binding by $50 \%$ of radioactively labeled angiotensin II to cell membrane preparations containing human $\mathrm{AT}$, receptors $\left(\mathrm{IC}_{50}\right.$ values)

\begin{tabular}{lll}
\hline & $\mathbf{I C}_{\mathbf{5 0}}(\mathbf{n M})$ & \\
\cline { 2 - 3 } & No drug washout & After drug washout \\
\hline Azilsartan & 2.6 & 7.4 \\
Olmesartan & 6.7 & 242.5 \\
Telmisartan & 5.1 & 191.6 \\
Irbesartan & 15.8 & $>10,000$ \\
Valsartan & 44.9 & $>10,000$ \\
\hline
\end{tabular}

Notes: $I C_{50}$ values obtained from the study of Ojima et al. in which angiotensin II radioligand binding to human $\mathrm{AT}$, receptors was tested in the presence of indicated drugs (no drug washout) and following a 5 -hour period after drug washout. ${ }^{42}$

Abbreviations: ARB, angiotensin II type I receptor blocker; $I C_{50}$, half maximal inhibitory concentration. 
labeled angiotensin II to cell membrane preparations containing human $\mathrm{AT}_{1}$ receptors. Under the experimental conditions described by Ojima et al, azilsartan was found to be approximately twice as potent as either olmesartan or telmisartan, both of which are considered to be among the most potent of all clinically approved ARBs for blocking angiotensin II binding to $\mathrm{AT}_{1}$ receptors. ${ }^{42}$ In addition, azilsartan was found to be about 5 to 20 times more potent than irbesartan and valsartan, respectively. The greater potency of azilsartan for $\mathrm{AT}_{1}$ receptor blockade could help explain why azilsartan lowers BP more than maximum approved doses of other ARBs such as olmesartan and valsartan.

It should be noted that the peak plasma concentration of azilsartan achieved after oral administration of the $80 \mathrm{mg}$ maximum approved dose of azilsartan medoxomil is $\sim 10$ micromolar. ${ }^{51}$ This is 5 times greater than the peak plasma concentration of olmesartan that is achieved after administration of the $40 \mathrm{mg}$ maximum approved dose of olmesartan medoxomil ( $\sim 2$ micromolar) ${ }^{52}$ This could help further explain the superior BP-lowering action of azilsartan versus olmesartan.

There are no published studies directly comparing the ability of azilsartan versus candesartan to inhibit binding of angiotensin II to human $\mathrm{AT}_{1}$ receptors in vitro. Candesartan is considered to have a very high potency for binding to human $\mathrm{AT}_{1}$ receptors relative to other $\mathrm{ARBs}$ and is known to be useful in controlling hypertension in both diabetic and nondiabetic patients. ${ }^{53,54}$ Some studies have indicated that the potency of candesartan is relatively similar to that of azilsartan for inhibiting binding of angiotensin II to bovine adrenal cortical membranes, blocking angiotensin II induced contraction of rabbit aorta, and acutely inhibiting pressor responses to intravenously infused angiotensin II. ${ }^{38,55}$ However, it should be noted that usual oral doses of azilsartan or azilsartan medoxomil yield peak concentrations of azilsartan in plasma that are 10 to 20 times greater than the concentrations of candesartan that are achieved with usual oral doses of candesartan cilexetil. ${ }^{51,56}$ This may help explain the results of recent studies from Japan where the maximum approved dose of azilsartan was found to lower BP significantly more than the maximum approved dose of candesartan cilexetil. ${ }^{28}$

\section{Very tight binding of azilsartan to $A T$, receptors}

One of the most unusual features of azilsartan reported to date is its ability to remain tightly bound to $\mathrm{AT}_{1}$ receptors for very long periods of time after drug washout. In studies of receptor binding of radioactively labeled angiotensin II conducted 5 hours after drug washout, azilsartan showed a superpotent ability to inhibit binding of angiotensin II to human $\mathrm{AT}_{1}$ receptors (IC50 values being more than 30-1000 fold lower for azilsartan than other ARBs including olmesartan, telmisartan, irbesartan, and valsartan, Table 1). ${ }^{42}$ Thus, in contrast to studies conducted without drug washout in which azilsartan appeared about 2-20 fold more potent than these other ARBs for blocking angiotensin II binding to human $\mathrm{AT}_{1}$ receptors, the studies conducted after drug washout showed azilsartan to be 30-1000 times more potent than the competitor ARBs. ${ }^{42}$

Time course studies of the ability of different ARBs to persistently block angiotensin II binding to $\mathrm{AT}_{1}$ receptors after drug washout have also indicated that azilsartan dissociates from $\mathrm{AT}_{1}$ receptors more slowly than other ARBs including olmesartan, telmisartan, and valsartan (Figure 4). ${ }^{42}$ These findings are consistent with separate studies conducted before and after drug washout indicating that azilsartan is more effective than other ARBs such as olmesartan or valsartan in persistently inhibiting angiotensin II-induced increases in $\mathrm{BP},{ }^{43}$ contraction of aortic vascular strips, ${ }^{42}$ cellular accumulation of inositol 1-phosphate, ${ }^{42}$ or activation of mitogen activated protein kinase (MAPK) in smooth muscle. ${ }^{57}$

There are no published time course studies that directly compare the ability of azilsartan versus candesartan to persistently inhibit in vitro binding of angiotensin II to $\mathrm{AT}_{1}$ receptors after drug washout. In humans, however, time course studies of the ability of different ARBs to inhibit pressor responses to intravenous angiotensin II have suggested that azilsartan may have slower dissociation kinetics from $\mathrm{AT}_{1}$ receptors than candesartan. ${ }^{55}$ In addition, in normotensive rats studied 24-hours after an oral dose of $1 \mathrm{mg} / \mathrm{kg}$, azilsartan appeared to inhibit the pressor response to intravenous angiotensin II considerably more than candesartan cilexetil (almost 100\% inhibition versus 65\% inhibition for azilsartan versus candesartan cilexetil, respectively). ${ }^{38}$ In spontaneously hypertensive rats (SHR) studied up to 24 hours after oral dosing, azilsartan also seemed to show a greater ability to maintain larger reductions in BP than candesartan cilexetil for a sustained period of time (ie, after plasma concentrations had presumably begun to wane). ${ }^{38}$ Taken together, these studies are consistent with the possibility, but do not prove, that azilsartan might bind to $\mathrm{AT}_{1}$ receptors more tightly than candesartan.

Is very "tight" binding of azilsartan to $\mathrm{AT}_{1}$ receptors clinically relevant? In patients who do not take their antihypertensive medications as prescribed and miss scheduled 


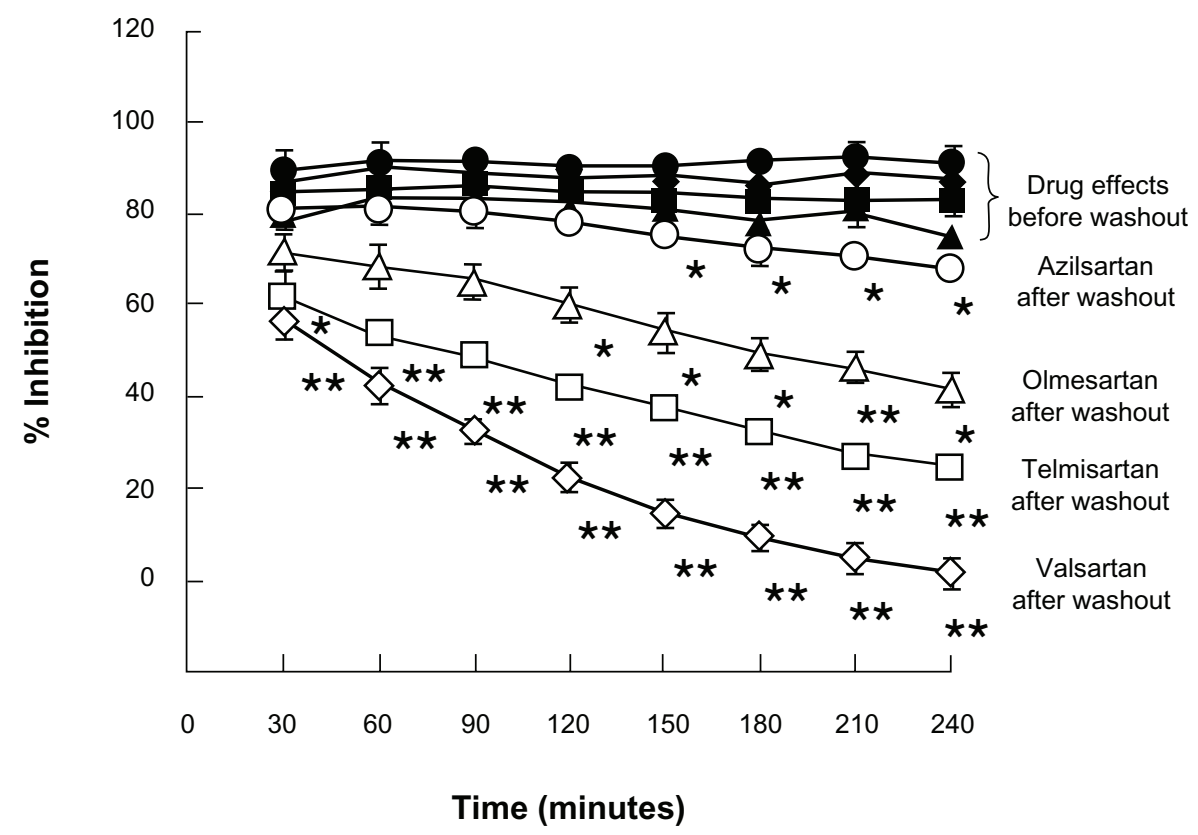

Figure 4 Time course of dissociation of azilsartan (circles), olmesartan (triangles), telmisartan (squares), and valsartan (diamonds) from human AT, receptor preparations as reported by Ojima et al. ${ }^{42}$

Notes: Membranes from Chinese hamster ovary cells expressing human AT, receptors were preincubated for 90 minutes with each ARB and further incubated with radioactively labeled angiotensin II for 240 minutes in the presence of the drugs (solid symbols) or after washout of the drugs (open symbols). Each ARB was tested at a concentration of $30 \mathrm{nM}$ except for valsartan which was tested at a concentration of $300 \mathrm{nM}$.

drug doses, it is theoretically conceivable that azilsartan's ability to tightly bind $\mathrm{AT}_{1}$ receptors for extended periods of time might afford a further degree of BP protection relative to other ARBs. Studies in animal models given a single dose of azilsartan have shown substantial reductions in BP that persist even when plasma drug levels are very low at 24 hours after dosing. ${ }^{38,43} \mathrm{In}$ addition, in conscious dogs with renal hypertension studied for 24 hours after one time oral dosing, the greater BP-lowering effect of $1 \mathrm{mg} / \mathrm{kg}$ azilsartan medoxomil versus $3 \mathrm{mg} / \mathrm{kg}$ olmesartan medoxomil appeared to become more prominent over time. ${ }^{43}$ It should be noted that the plasma half-life of azilsartan is similar to, or even somewhat shorter than that of olmesartan. Thus, the studies showing relatively prolonged functional effects of azilsartan compared to other ARBs cannot be readily explained by simple pharmacokinetic differences between the drugs.

Although the relatively unusual ability of azilsartan to tightly bind $\mathrm{AT}_{1}$ receptors could conceivably offer cardioprotective advantages over other ARBs in patients who do not take their medications on a consistent basis, the potential clinical relevance of prolonged $\mathrm{AT}_{1}$ receptor binding in patients who carefully take their medications as prescribed is less clear. ${ }^{58}$ To the extent that patients faithfully take their medications and chronically maintain expected steady state drug levels, the rate at which different ARBs dissociate from $\mathrm{AT}_{1}$ receptors should have relatively little effect on their ability to control BP over 24 hours. In patients who chronically take maximum approved doses of ARBs, there is little or no evidence that azilsartan's superior ability to lower $\mathrm{BP}$ versus other ARBs is any more pronounced at 24 hours after dosing than it is at 1 hour after dosing. In most of the head-to-head clinical trials that have compared chronic therapy with azilsartan versus other ARBs, the superior antihypertensive effect of azilsartan appeared to be fairly consistent across the entire 24-hour dosing interval. ${ }^{25}$ Interestingly, however, in Japanese patients studied by ambulatory BP monitoring after treatment with azilsartan or candesartan cilexetil for 14 weeks, the trough to peak ratios for systolic and diastolic $\mathrm{BP}$ appeared greater in the azilsartan group ( 0.97 and 0.95 for systolic BP and diastolic BP, respectively) than in the candesartan cilexetil group ( 0.82 and 0.75 for systolic $\mathrm{BP}$ and diastolic BP, respectively). ${ }^{28}$ This raises the possibility that in some circumstances or patient groups, the superior BP-lowering effects of azilsartan over candesartan cilexetil or other ARBs might become more pronounced towards the end of the 24-hour dosing interval.

\section{Additional effects beyond AT, receptor blockade and BP-lowering}

While azilsartan might be the most potent $\mathrm{AT}_{1}$ receptor blocker available and may reduce 24-hour BP significantly more than maximum approved doses of other ARBs such 
as olmesartan, valsartan, and candesartan, it remains to be determined whether azilsartan will offer further clinical benefits beyond those afforded by its robust ability to inhibit the renin angiotensin system and lower BP. Recent preclinical studies have indicated that azilsartan may have beneficial effects on cellular mechanisms of cardiometabolic disease through actions that could involve more than just blockade of $\mathrm{AT}_{1}$ receptors and/or reduction in $\mathrm{BP}^{57}$ For example, Kajiya et al have reported that azilsartan is a pleiotropic ARB with antiproliferative effects in cultured vascular cells that may not strictly depend on $\mathrm{AT}_{1}$ receptor blockade. ${ }^{57}$ In addition, in studies in 3T3L1 cells, azilsartan has been found to promote adipocyte differentiation and stimulate expression of genes encoding peroxisome proliferator activated receptors, leptin, adipsin, and adiponectin more than valsartan. ${ }^{57}$ Studies in animal models have also shown that azilsartan or azilsartan medoxomil in doses similar to those used in humans can improve insulin sensitivity much more than larger doses of other ARBs such as olmesartan medoxomil or candesartan cilexetil. ${ }^{43,59}$ These observations could serve to motivate clinical studies comparing the metabolic benefits of azilsartan versus other ARBs in use today. Finally, in studies in a rat model of type 2 diabetes, azilsartan medoxomil appeared to be more potent than olmesartan medoxomil in reducing proteinuria. ${ }^{43}$ However, it remains to be determined whether any greater antiproteinuric effects of azilsartan are related to its superior ability to block $\mathrm{AT}_{1}$ receptors and reduce $\mathrm{BP}$ or to some other special property of the drug.

\section{Summary}

Based on studies conducted to date, azilsartan appears to: (1) be more potent than most if not all other clinically available ARBs for inhibiting binding of angiotensin II to human $\mathrm{AT}_{1}$ receptor membrane preparations; (2) dissociate from $\mathrm{AT}_{1}$ receptors much more slowly than other ARBs; and (3) reduce 24-hour BP in hypertensive humans without serious comorbidities more effectively than maximum approved doses of the well-known ARBs olmesartan, valsartan, and candesartan, each of which is considered to be more effective in lowering BP than losartan. However, the antihypertensive effects of azilsartan in hypertensive patients with serious comorbidities remain to be determined. Preclinical studies have indicated that azilsartan improves insulin sensitivity more than candesartan and olmesartan, and may have pleiotropic effects beyond $\mathrm{AT}_{1}$ receptor blockade of potential metabolic and cardiovascular significance. However, clinical trials will be required to determine whether azilsartan offers further benefits beyond BP-lowering. As noted by many scientific authorities and as stated by the FDA, "it is the decrease in BP, rather than any other property of (antihypertensive) drugs, that is largely responsible" for their cardiovascular clinical benefits. Because the relationship between cardiovascular risk and BP is monotonic with absolute risk decreasing progressively as BP decreases towards recommended goals, the greater antihypertensive effects of azilsartan serve to justify clinical interest in this recently approved ARB relative to other molecules in the class with a lower capacity to reduce BP.

\section{Disclosures}

TWK has received grant funding from the National Institutes of Health and lecture honoraria from GlaxoSmithKline, Boehringer-Ingelheim, Takeda Pharmaceuticals North America, Shionogi, Pfizer, and Merck and has served as a consultant for Theravance Inc, Takeda Pharmaceuticals North America, and Daiichi Sankyo Pharmaceuticals, and holds stock ownership interest in GlaxoSmithKline, Bethesda Pharmaceuticals, Ligand Pharmaceuticals, Novartis, and Pfizer. TK has no potential conflicts of interest to declare.

\section{References}

1. Ram CV. Angiotensin receptor blockers: current status and future prospects. Am J Med. 2008;121(8):656-663.

2. Furukawa Y, Kishimoto S, Nishikawa K, inventors; Takeda Chemical Industries, Ltd, Osaka, Japan, assignee. Hypotensive imidazole-5-acetic acid derivatives. US Patent 4,355,040. October 20, 1982.

3. Furukawa Y, Kishimoto S, Nishikawa K, inventors; Takeda Chemical Industries, Ltd., Osaka, Japan, assignee. Hypotensive imidazole derivatives. US Patent 4,340,598, July 20, 1982.

4. Duncia JV, Chiu AT, Carini DJ, et al. The discovery of potent nonpeptide angiotensin II receptor antagonists: a new class of potent antihypertensives. J Med Chem. 1990;33(5):1312-1329.

5. Takeda Pharmaceuticals North America. Edarbi prescribing information. 2011.

6. Takeda Pharmaceuticals Press Release. Takeda's Edarbi ${ }^{\circledR}$ (azilsartan medoxomil) receives European marketing authorisation for the treatment of essential hypertension. Available from: http://www.takeda. com/press/article_43967.html. Accessed January 27, 2012.

7. Takeda Pharmaceuticals Press Release. New drug application approval for AZILVA $^{\circledR}$ in Japan, a treatment of hypertension. Available from: http:// www.takeda.com/press/article_44965.html. Accessed January 26, 2012.

8. Staessen JA, Richart T, Wang Z, Thijs L. Implications of recently published trials of blood pressure-lowering drugs in hypertensive or high-risk patients. Hypertension. 2010;55(4):819-831.

9. Griffin KA, Bidani AK. Progression of renal disease: renoprotective specificity of renin-angiotensin system blockade. Clin J Am Soc Nephrol. 2006;1(5):1054-1065.

10. Food and Drug Administration, Center for Drug Evaluation and Research. Guidance for industry. Hypertension indication: drug labeling for cardiovascular outcome claims. United States Department of Health and Human Services. 2011. Available from: http://www.fda. gov/downloads/drugs/GuidanceComplianceRegulatoryInformation/ Guidances/ucm075072.pdf

11. Mancia G, Laurent S, Agabiti-Rosei E, et al. Reappraisal of European guidelines on hypertension management: a European Society of Hypertension Task Force document. J Hypertens. 2009;27(11):2121-2158. 
12. Oparil S, Silfani TN, Walker JF. Role of angiotensin receptor blockers as monotherapy in reaching blood pressure goals. Am J Hypertens. 2005;18(2 Pt 1):287-294.

13. Ram CV, Ramaswamy K, Qian C, et al. Blood pressure outcomes in patients receiving angiotensin II receptor blockers in primary care: a comparative effectiveness analysis from electronic medical record data. J Clin Hypertens (Greenwich). 2011;13(11):801-812.

14. Petrella R, Michailidis P. Retrospective analysis of real-world efficacy of angiotensin receptor blockers versus other classes of antihypertensive agents in blood pressure management. Clin Ther. 2011;33(9):1190-1203

15. Unger T. Significance of angiotensin type 1 receptor blockade: why are angiotensin II receptor blockers different? Am J Cardiol. 1999;84(10 A):9S-15S.

16. Song JC, White CM. Pharmacologic, pharmacokinetic, and therapeutic differences among angiotensin II receptor antagonists. Pharmacotherapy. 2000;20(2):130-139.

17. Burnier M. Angiotensin II type 1 receptor blockers. Circulation. 2001;103(6):904-912.

18. Giles TD, Oparil S, Silfani TN, Wang A, Walker JF. Comparison of increasing doses of olmesartan medoxomil, losartan potassium, and valsartan in patients with essential hypertension. J Clin Hypertens (Greenwich). 2007;9(3):187-195.

19. Kassler-Taub K, Littlejohn T, Elliott W, Ruddy T, Adler E. Comparative efficacy of two angiotensin II receptor antagonists, irbesartan and losartan in mild-to-moderate hypertension. Irbesartan/Losartan Study Investigators. Am J Hypertens. 1998;11(4 Pt 1):445-453.

20. Oparil S, Guthrie R, Lewin AJ, et al. An elective-titration study of the comparative effectiveness of two angiotensin II-receptor blockers, irbesartan and losartan. Irbesartan/Losartan Study Investigators. Clin Ther. 1998;20(3):398-409.

21. Smith DH, Cramer MJ, Neutel JM, Hettiarachchi R, Koval S. Comparison of telmisartan versus losartan: meta-analysis of titration-to-response studies. Blood Press Monit. 2003;8(3):111-117.

22. Weir MR, Punzi HA, Flack JM, et al. A randomized, double-blind, forced-titration study to compare olmesartan medoxomil versus losartan potassium in patients with stage 1 and 2 hypertension. Postgrad Med. 2011;123(1):80-87.

23. Zannad F, Fay R. Blood pressure-lowering efficacy of olmesartan relative to other angiotensin II receptor antagonists: an overview of randomized controlled studies. Fundam Clin Pharmacol. 2007;21(2):181-190.

24. Nixon RM, Muller E, Lowy A, Falvey H. Valsartan vs other angiotensin II receptor blockers in the treatment of hypertension: a meta-analytical approach. Int J Clin Pract. 2009;63(5):766-775.

25. White WB, Weber MA, Sica D, et al. Effects of the angiotensin receptor blocker azilsartan medoxomil versus olmesartan and valsartan on ambulatory and clinic blood pressure in patients with stages 1 and 2 hypertension. Hypertension. 2011;57(3):413-420.

26. Bakris GL, Sica D, Weber M, et al. The comparative effects of azilsartan medoxomil and olmesartan on ambulatory and clinic blood pressure. J Clin Hypertens (Greenwich). 2011;13(2):81-88.

27. Sica D, White WB, Weber MA, et al. Comparison of the novel angiotensin II receptor blocker azilsartan medoxomil vs valsartan by ambulatory blood pressure monitoring. J Clin Hypertens (Greenwich). 2011;13(7):467-472.

28. Rakugi H, Enya K, Sugiura K, Ikeda Y. Comparison of the efficacy and safety of azilsartan with that of candesartan cilexetil in Japanese patients with grade I-II essential hypertension: a randomized, doubleblind clinical study. Hypertens Res. 2012. [Epub ahead of print.]

29. Staessen JA, Thijs L, Li Y, et al. 'Beyond blood pressure' means multiple risk factor intervention, not pleiotropic antihypertensive drugs. Curr Opin Cardiol. 2007;22(4):335-343.

30. Turnbull F, Neal B, Pfeffer M, et al. Blood pressure-dependent and independent effects of agents that inhibit the renin-angiotensin system. J Hypertens. 2007;25(5):951-958.

31. Nathan DM. Navigating the choices for diabetes prevention. $N$ Engl J Med. 2010;362(16):1533-1535.
32. The NAVIGATOR Study Group. Effect of valsartan on the incidence of diabetes and cardiovascular events. $N$ Engl J Med. 2010;362(16): 1477-1490.

33. Bakris G. Are there effects of renin-angiotensin system antagonists beyond blood pressure control? Am J Cardiol. 2010;105(1 Suppl): 21A-29A.

34. Bakris G, Burgess E, Weir M, Davidai G, Koval S, Investigators AS. Telmisartan is more effective than losartan in reducing proteinuria in patients with diabetic nephropathy. Kidney Int. 2008;74(3):364-369.

35. Knowler WC, Fowler SE, Hamman RF, et al. 10-year follow-up of diabetes incidence and weight loss in the Diabetes Prevention Program Outcomes Study. Lancet. 2009;374(9702):1677-1686.

36. Crandall JP, Knowler WC, Kahn SE, et al. The prevention of type 2 diabetes. Nat Clin Pract Endocrinol Metab. 2008;4(7):382-393.

37. Tocci G, Paneni F, Palano F, et al. Angiotensin-converting enzyme inhibitors, angiotensin II receptor blockers and diabetes: a meta-analysis of placebo-controlled clinical trials. Am J Hypertens. 2011;24(5):582-590.

38. Kohara Y, Imamiya E, Kubo K, Wada T, Inada Y, Naka T. A new class of angiotensin II receptor antagonists with a novel acidic bioisostere. Bioorganic Medicinal Chemistry Letters. 1995;5(17):1903-1908.

39. Kohara Y, Kubo K, Imamiya E, Wada T, Inada Y, Naka T. Synthesis and angiotensin II receptor antagonistic activities of benzimidazole derivatives bearing acidic heterocycles as novel tetrazole bioisosteres. J Med Chem. 1996;39(26):5228-5235.

40. Naka T, Kubo K. A new class of diacidic nonpeptide angiotensin II receptor antagonists: candesartan cilexetil. Curr Pharm Des. 1999;5(6): 453-472.

41. Baker WL, White WB. Azilsartan medoxomil: a new angiotensin II receptor antagonist for treatment of hypertension. Ann Pharmacother. 2011;45(12):1506-1515.

42. Ojima M, Igata $\mathrm{H}$, Tanaka $\mathrm{M}$, et al. In vitro antagonistic properties of a new angiotensin type 1 receptor blocker, azilsartan, in receptor binding and function studies. J Pharmacol Exp Ther. 2011;336(3):801-808.

43. Kusumoto K, Igata H, Ojima M, et al. Antihypertensive, insulinsensitising and renoprotective effects of a novel, potent and long-acting angiotensin II type 1 receptor blocker, azilsartan medoxomil, in rat and dog models. Eur J Pharmacol. 2011;669(1-3):84-93.

44. McAdams MA, Governale LA, Swartz L, Hammad TA, Dal Pan GJ. Identifying patterns of adverse event reporting for four members of the angiotensin II receptor blockers class of drugs: revisiting the Weber effect. Pharmacoepidemiol Drug Saf. 2008;17(9):882-889.

45. Turnbull F, Neal B, Ninomiya T, et al. Effects of different regimens to lower blood pressure on major cardiovascular events in older and younger adults: meta-analysis of randomised trials. $B M J$. 2008;336(7653):1121-1123.

46. Julius S, Kjeldsen SE, Weber M, et al. Outcomes in hypertensive patients at high cardiovascular risk treated with regimens based on valsartan or amlodipine: the VALUE randomised trial. Lancet. 2004;363(9426):2022-2031.

47. Kaplan NM. The choice of thiazide diuretics: why chlorthalidone may replace hydrochlorothiazide. Hypertension. 2009;54(5):951-953.

48. Messerli FH, Bangalore S. Half a century of hydrochlorothiazide: facts, fads, fiction, and follies. Am J Med. 2011;124(10):896-899.

49. Takeda Pharmaceuticals North America. Edarbyclor prescribing information. 2012. Available from: http:/www.tpna.com/newsroom/ press_release_detail.aspx?year=2012\&id=231. Accessed February 13, 2012.

50. Zaiken K, Cheng JW. Azilsartan medoxomil: a new angiotensin receptor blocker. Clin Ther. 2011;33(11):1577-1589.

51. Center for Drug Evaluation and Research. Azilsartan medoxomil clinical pharmacology and biopharmaceutics review. New drug application to the Food and Drug Administration 2010; NDA 200796: 1-26. Available from: http://www.accessdata.fda.gov/drugsatfda_docs/ nda/2011/200796Orig1 s000ClinPharmR.pdf. Accessed July 14, 2011.

52. Schwocho LR, Masonson HN. Pharmacokinetics of CS-866, a new angiotensin II receptor blocker, in healthy subjects. J Clin Pharmacol. 2001;41(5):515-527. 
53. Van Liefde I, Vauquelin G. Sartan-AT, receptor interactions: in vitro evidence for insurmountable antagonism and inverse agonism. Mol Cell Endocrinol. 2009;302(2):237-243.

54. Feghali RE, Nisse-Durgeat S, Asmar R. Effect of candesartan cilexetil on diabetic and non-diabetic hypertensive patients: meta-analysis of five randomized double-blind clinical trials. Vasc Health Risk Manag. 2007;3(1):165-171.

55. Csajka C, Buclin T, Fattinger K, Brunner HR, Biollaz J. Population pharmacokinetic-pharmacodynamic modelling of angiotensin receptor blockade in healthy volunteers. Clin Pharmacokinet. 2002;41(2):137-152.
56. Gleiter CH, Morike KE. Clinical pharmacokinetics of candesartan. Clin Pharmacokinet. 2002;41(1):7-17.

57. Kajiya T, Ho C, Wang J, Vilardi R, Kurtz TW. Molecular and cellular effects of azilsartan: a new generation angiotensin II receptor blocker. J Hypertens. 2011;29(12):2476-2483.

58. Vauquelin G, Van Liefde I. Slow antagonist dissociation and longlasting in vivo receptor protection. Trends Pharmacol Sci. 2006; 27(7):356-359.

59. Iwai M, Chen R, Imura Y, Horiuchi M. TAK-536, a new AT receptor blocker, improves glucose intolerance and adipocyte differentiation. Am J Hypertens. 2007;20(5):579-586.

\section{Publish your work in this journal}

Vascular Health and Risk Management is an international, peerreviewed journal of therapeutics and risk management, focusing on concise rapid reporting of clinical studies on the processes involved in the maintenance of vascular health; the monitoring, prevention and treatment of vascular disease and its sequelae; and the involvement of metabolic disorders, particularly diabetes. This journal is indexed on PubMed Central and MedLine. The manuscript management system is completely online and includes a very quick and fair peer-review system, which is all easy to use. Visit http://www.dovepress.com/ testimonials.php to read real quotes from published authors.

Submit your manuscript here: http://www.dovepress.com/vascular-health-and-risk-management-journal 